Michal Titko - Jan Havko - Jana Studena

\title{
MODELLING RESILIENCE OF THE TRANSPORT CRITICAL INFRASTRUCTURE USING INFLUENCE DIAGRAMS
}

The article discusses the possible impact of disasters on functionality of the transport critical infrastructure elements by overcoming their resilience. The aim of the article is to provide an appropriate approach to the resilience measurement through understanding of this close relationship. It was achieved by using combination of (1) a decisiontheoretical approach based on Influence Diagrams, which was used as a tool to model functionality disruption level of transportation network elements after disaster impact and (2) the time decomposition of the functionality disruption duration of these elements. Based on this approach, the transportation network element resilience assessment was conducted in form of the transportation element resilience loss. The proposed approach is intended to be applied to the critical infrastructure elements rather than to the transportation network as a whole.

Keywords: resilience, disasters, risk reduction, critical infrastructure, transportation, influence diagrams

\section{Introduction}

Over the last decades, there is a considerable research interest and ongoing discussions on the topic of the transportation network (TN) resilience from both practitioners' and academic communities. Several approaches to the $\mathrm{TN}$ resilience understanding and measurement have been proposed and the variety of research perspectives including those from the disaster or hazard perspective were introduced. The resilience of the TN has become an important issue in ensuring operational continuity [1] of the TN and in providing of a TN key function - to provide means to move people and goods between the origin and destination [2-3].

Importance of resilience issue increases with severity of possible consequences caused by a TN disruption. Under certain circumstances, the disruption of the TN can cause problems in ensuring the national priorities such as economic sustainability [4] and growth, human welfare [4], social development, providing security and public order [5-6], operational capability of the armed forces [5]; it plays a critical role in delivering disaster relief or facilitating mass evacuations, but plays an important role in disaster management, as well [7-9]. Those examples of consequences can be relevant only (1) in cases of the large-scale disruptions of a TN or (2) for a small part of a dense TN of every state, which can be considered as truly important. The second option results in identification of the critical infrastructure (CI) notion - a subset of the transportation infrastructure that is of the particular importance and interest, which is of interest in this article.

Based on relation of a TN element performance/ functionality disruption, caused by a disaster and its resilience overcoming, this paper describes the approach to the resilience measurement suitable for the transportation CI elements. That implies focus on the resilience of TN elements in particular, rather than the $\mathrm{TN}$ as a whole. There are still properties of the systematic approach in form of demand change distribution after a disaster occurrence. From this reason, but not limited to, a decision-theoretical approach, based on Influence Diagrams (IDs), was used in this paper. It was used as a tool to model functionality disruption of the TN elements after disaster occurrence. It is argued that the use of IDs can address two important aspects of resilience modelling: (1) provide an improved framework for the risk and resilience assessment through more elaborate combining probabilities and measures of disruption levels after a disaster with respect to not only a direct influence (loss of capacity due to disaster) but also to often neglected an indirect influence of a disaster (change of demand distribution in $\mathrm{TN}$ ) and (2) facilitate knowledge elicitation from human experts through a structured approach to the problem. Moreover, the approach is complemented by the time decomposition of the functionality disruption duration of the $\mathrm{TN}$ elements with respect to all the relevant resilience features (robustness, redundancy, resourcefulness, responsiveness, recoverability).

\section{Background and rationale}

The resilience concept originated from ecology [10-11] and has been continuously enhanced into other areas [12], e.g. business and economics [13], telecommunication systems [14], power systems [15-16], production systems

Michal Titko ${ }^{1, *}$, Jan Havko², Jana Studena

${ }^{1}$ Faculty of Security Engineering, University of Zilina, Slovakia

${ }^{2}$ Henkel Slovensko, Bratislava, Slovakia

*E-mail of corresponding author: michal.titko@fbi.uniza.sk 
and supply chains [17], water distribution systems [18], health care systems [19], as well as infrastructure systems in general [20]. There are several applications and approaches to the resilience assessment in transport [21-28] and transportation systems. In technical systems, resilience is perceived as an ability of the system to absorb disturbance, to tolerate the negative changes of the system, while ensuring the basic (essential) functions, structure and identity of the system [29].

Resilience of the CI is rather new and has been intensified especially due to increasing dependency of societies on critical infrastructures services [30-31] and in terms of disasters, such as Fukushima disaster. According to Bruneau et al. [32] and O'Rourke [33], the CIs would be resilient if they were characterized by systems that are robust (robustness), redundant (redundancy), resourceful (resourcefulness) and capable of rapid response (responsiveness or rapidity). Based on the research approach of different authors and subject under analysis, there can be found other features, which characterize resilience of a system (e.g. preparedness/preparation [3435], recoverability [34-37], absorption [38], adaptation [3738]). In definition and description of all the mentioned features, an overlapping and similarities in explanation can be observed. For the purpose of the paper and better understanding of the main features used for the following resilience assessment, their definitions are provided:

- robustness - the inherent strength (also resistance [33]), or the ability of elements, systems and other measures of analysis to withstand a given level of stress or demand without suffering degradation or loss of function [33, 39-40],

- redundancy - the extent to which elements, systems, or other measures of analysis exist that are substitutable, i.e., capable of satisfying functional requirements in the case of disruption, degradation, or loss of functionality [15],

- resourcefulness - the capacity to identify problems, establish priorities [39], mobilize needed resources and services in emergencies [33, 39] and mobilize resources in the process of recovery [39].

- $\quad$ responsiveness - the capability of the system to respond to changes of an environment and activate the forces and means [36] aimed at dealing with the impacts of disaster in order to protect an CI element functionality. In this article is argued that more resilient system response activities should start before a disaster occurs (when risk determinants change), followed by elimination of the function degradation activities in time of the disaster effects.

- recoverability - responsiveness is continuously followed by renewal (recovery) of the element main function. It is the ability to recover the desired functionality level after a disaster [34, 36]. Some authors understood recovery processes as the part of responsiveness feature [33, 39], but in opinion of these authors the recovery processes differ greatly from response activities and therefore they should be assessed separately.

Apparently, all the features can be divided into two main groups: (1) features which represent inner (structural) ability of the system or element to withstand the negative effects of a disaster - robustness, absorption and redundancy; (2) features which represent external ability of responsible authorities (crisis managers or object operators) to protect and recover main function of a particular element - preparedness, responsiveness, resourcefulness, recoverability, etc. This categorisation will be address in the following assessment because it is important to consider the fact that a CI element can suffer operational disturbance (e.g. due to high snow level) but it still can be without structural damage.

Differences between resilience assessment approaches and frameworks mentioned above are basically in assessment methodology and final expression of resilience. In majority of quantitative methodologies a large number of properties are needed [41], which seems to be one of the main inconveniences within resilience evaluation that should be addressed. From disaster and hazard perspective, is very important to capture stochastic nature of disaster occurrence and its influence on resilience evaluation. Moreover, here is argued that the particularities of a system/ subject under analysis (within this paper it is dealt with the TN elements and CI elements in particular) should be more precisely incorporated into resilience assessment in order to propose an appropriate approach for that system/ subject assessment. In order to address all of these features in resilience assessment, a new modified approach is proposed, which is based on Influences Diagrams (IDs).

\section{Methodology - approach to transportation element resilience assessment}

Resilience reflects the ability of an element or a system to ensure its function(s) in conditions of effects of external and internal factors [42]. The effects of a threat can disrupt the core function(s) of the system, in this case the transport system with core function ensuring population mobility and goods movement $[3,5]$, by overcoming the resilience of the element. To what extent the resilience is distorted/disturbed, to a corresponding extent the functionality and operability of the CI element is disturbed too. This rate of disruption is assumed as one of variable for expression of resilience. The functionality range from $100 \%$ (full performance) to $0 \%$ (total disruption) is assumed. Moreover, there are significant differences in cases of short-term and long-term functionality disturbance and therefore it is claimed that the time factor (time variable) should be incorporated into the resilience assessment.

Following the mentioned facts, the two main variables of the TN element resilience assessment are assumed, namely:

- to what extent the functionality of an element may be disrupted (if ever) - Disruption rate assessment, 


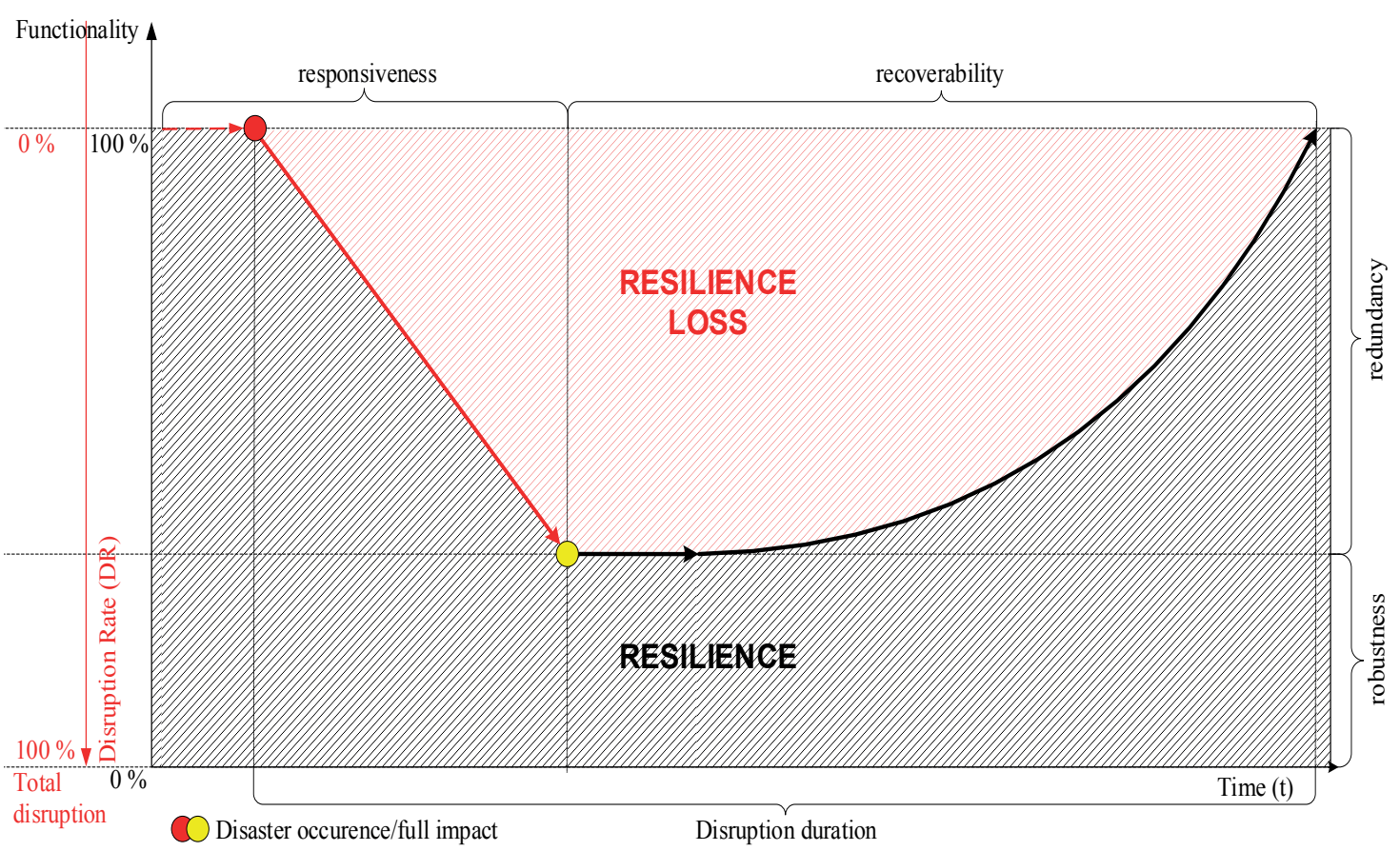

Figure 1 Example of a TN element disruption profile with incorporating corresponding resilience features - conceptual definition

- $\quad$ how long a disruption may take - Disruption duration assessment.

Several studies have proposed infrastructure disruption profile [34-35, 37, 41, 43-44] to capture resilience or resilience loss, each with some common (normal conditions, disruption state, recovery) and specific issues considered. Such a profile seems to be an appropriate tool to illustrate and capture the basic relations between variables which define a notion of resilience. In order to capture relation between here defined variables (disruption rate and disruption duration), taking into account all the resilience key features, the concept illustrated in Figure 1 is used as a conceptual definition of resilience notion. This concept is closely described in sections 3.2-3.6.

As shown in Figure 1, resilience is of a continuous nature (keeps the same value if nothing happens), so it will be more appropriate to evaluate the resilience of the TN element by expressing its predicted loss rate. Therefore, the loss of the CI resilience can be measured as the expected loss in quality of its provided function (Disruption Rate DR) over the time (Disruption Duration - DT) [33], simply captured in equation:

$$
\text { Resilience Loss }=f(D R, D T)
$$

The purpose is to produce a numeric measure that would quantify the notion of resilience.

\subsection{Disruption rate}

In order to express the Disruption rate of a TN element within resilience assessment, it should be clear what will be understood as a failure or functionality disruption. A disruption of a transportation element can be defined in terms of reliability of an element to perform its main function [7]. As an important characteristics of the CI element to perform its function is considered its capacity [9]. The possible loss of that quantity can be considered as a failure measure. Basically, the reduction or the loss of capacity can be caused by physical (structural) damage or physical obstacles on the road. Moreover, there is the second performance issue we should take into consideration an ability of a TN element to satisfy the transportation demand. The rate of satisfaction of that need is assumed as the second failure measure. Therefore, the two main aspects of the CI elements functionality disruption are assumed:

- direct disruption, which is understood as the impact on CI element capacity - Capacity loss,

- indirect disruption - change in traffic distribution resulting in effects on demand on a TN element or the TN as whole - Demand change.

Both impacts have an effect on the main function of a TN element and therefore their combination can provide overall value for the TN element functionality loss - called the Disruption rate. However, while the Capacity loss is considered only in a negative perspective (only loss of the capacity is considered), Demand change can be considered in a positive perspective, as well (a positive effect on the $\mathrm{TN}$ element functionality) because hazard and disaster effects may result also into decreasing demand on the $\mathrm{TN}$. In order to capture these different perspectives, we assume Influence Diagrams as an appropriate tool to model Disruption rate. The modelling procedure is described in subsection 3.1.3. 
Table 1 Categorisation of Capacity loss

\begin{tabular}{|c|c|}
\hline Levels of Capacity loss & Explanation \\
\hline Nominal or no limitation & $\begin{array}{l}\text { Managing the situation by common means, maintenance and management; comparing the } \\
\text { maximum construction capacity and the utilization rate of the transportation element; some TN } \\
\text { elements have a reserve that guarantees the required capacity despite the disaster. }\end{array}$ \\
\hline Low limitation & $\begin{array}{l}\text { Effect on traffic capacity is low - remaining capacity is able to handle the traffic demands with } \\
\text { some minor delays resulting from the reduced speed limit, rescue activities, etc. }\end{array}$ \\
\hline Significant limitation & $\begin{array}{l}\text { Traffic demand is not fully satisfied or it is satisfied with significant delays - there are delays due to } \\
\text { obstacles (debris) on the transport element, or due to transport route conditions; for some types } \\
\text { of vehicles (e.g. trucks) the transition can be temporarily disabled - the alternative routes are } \\
\text { applied (redundancy feature takes place). }\end{array}$ \\
\hline Partial collapse & $\begin{array}{l}\text { Complete loss of the capacity - due to structural damages (on surface, static, etc.) use of an } \\
\text { element is forbidden and long-lasting disruption is assumed. }\end{array}$ \\
\hline Total collapse & $\begin{array}{l}\text { Complete loss of the capacity - in the worst cases destruction of an element without recovery } \\
\text { option is assumed. }\end{array}$ \\
\hline
\end{tabular}

The Disruption rate is considered as an overall failure measure and represent a loss in quality of provided function by the TN element. A scale from 0 to 1 (with the corresponding transformation into percentage values from $0 \%$ to 100\%) is assumed for the Disruption rate, with increasing values indicating higher functionality loss.

\subsubsection{Capacity loss - the direct disruption of the functionality of the transport critical infrastructure}

There are several reasons causing transportation element capacity reduction or loss. They are mainly external - disasters, traffic accidents, etc., or internal - incidents, maintenance and repairs. The rate of loss is dependent on the disaster type, its intensity and severity. The scope of present assessment are external triggers, especially disasters and man-made incidents (e.g. floods, earthquake damages, heavy snow load, wind storm, traffic accident, etc.), while the internal factors can also cause long-lasting capacity reduction, but the realisation is scheduled (repairs) and appropriate measures are put in place to prevent traffic complications. The capacity loss rate can be categorised as it is shown in Table 1.

\subsubsection{Demand change - the indirect disruption of the functionality of the transport critical infrastructure}

In addition to the direct impact of a disaster on capacity, each hazard can produce demand on the TN (cause people to use transportation network). Demand on a TN element can be decreased as well as increased which also depend on current situation, disaster location, the possibility of using both driving directions in case of mass evacuation and other TN links availability [6], etc. The demand factor, whether increased or decreased, has influence on the TN element performance only and causes no structural damage to a $\mathrm{TN}$ element. If a disaster or accident causes a decreased demand on a TN element, it could have a positive effect on the resilience rate and vice versa. To withstand negative effects of a demand change could be a case for more $\mathrm{TN}$ elements (due to already rising traffic intensity in normal conditions), for the CI elements in particular. Therefore, it seems to be a necessary variable to be taken into account within the resilience assessment. Basically, one understands the ability to manage demand change distribution over the $\mathrm{TN}$ as the redundancy feature of the TN element resilience. For the demand change factor the following levels are assumed: Lowered, Normal, Increased and Mass Evacuation. Changing demand (if one expects any level of increased demand) for a given TN element can be addressed by other elements of the network, among which the changed demand is distributed [45]. In order to ensure replacement of the disrupted element, in some cases, the element can be temporarily replaced by a makeshift element (e.g. a makeshift bridge); usually it would be an element with lower capacity serving as a temporary substitution; sufficient for the time being. Planning such a measure can increase redundancy of the whole TN and an element in particular.

\subsubsection{Modelling disruption rate using influence diagrams}

The influence diagram is a probabilistic decision model that is a more compact representation of a decision problem than a decision tree [46]. The ID captures dependencies between variables in the modelled domain, which seems to be appropriate to capture relationship between direct and indirect disruption of the functionality of the CI transportation element. This property allows for more compact and efficient (especially in terms of knowledge elicitation) representation of the problem, implying that it is suitable for larger scale decision problems.

There are three types of variables (nodes) in ID: (1) chance nodes that capture unknown events and relevant probabilities including probabilistic dependencies (by means of conditional probabilities), (2) utility nodes that 


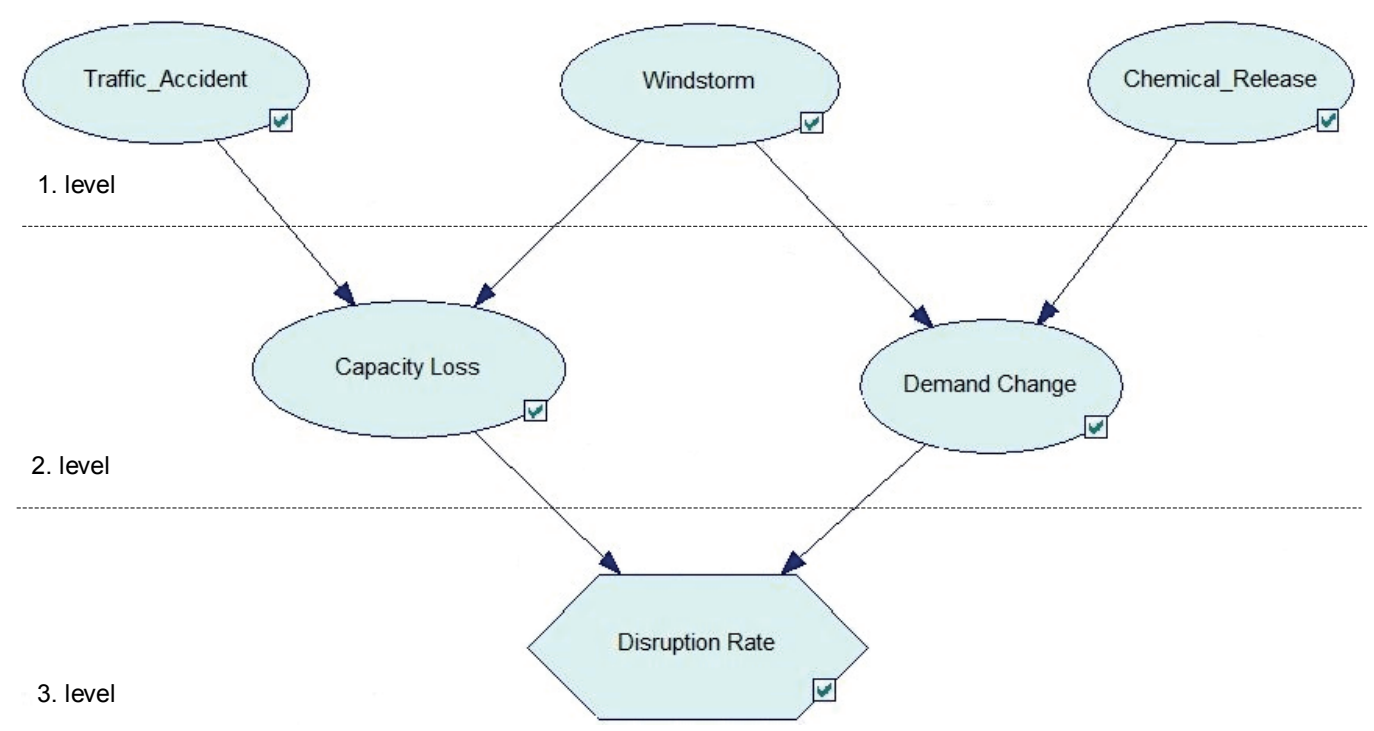

Figure 2 A simple example of the ID model

Table 2 An example of model definition for the node Capacity loss

\begin{tabular}{lcccc}
\hline Windstorm & \multicolumn{2}{c}{ Present } & \multicolumn{3}{c}{ Absent } \\
Traffic accident & Present & Absent & Present & Absent \\
\hline Nominal or No Limitation & 0.05 & 0.1 & 0.045 & 1 \\
Low Operability Limitation & 0.35 & 0.5 & 0.45 & 0 \\
Significant Operability Limitation & 0.59 & 0.395 & 0.5 & 0 \\
Partial Collapse & 0.008 & 0.004 & 0.004 & 0 \\
Total Collapse & 0.002 & 0.001 & 0.001 & 0 \\
\hline
\end{tabular}

Table 3 An example of model definition for the node Demand using the noisy-average model

\begin{tabular}{cccccc}
\hline $\begin{array}{c}\text { Parent (Weight) } \\
\text { State }\end{array}$ & Present & Absent & Present & Absent & LEAK(1) \\
\hline Lowered & 0 & 0 & 0.3 & 0 & 0 \\
Normal & 0.2 & 1 & 0.7 & 1 & 0 \\
Increased & 0.3 & 0 & 0 & 0 & 0 \\
Mass Evacuation & 0.5 & 0 & 0 & 0 & 0 \\
\hline
\end{tabular}

encode utilities (which can be costs, profits, etc.) that define user's preferences over the set of outcomes and (3) decision nodes that define elements of the domain over which the decision maker has the complete control [47].

To model the overall disruption of the CI element functionality it is proposed to define a measure which capture this quality (Disruption rate). In order to define this rate a structured approach, based on IDs, is proposed. We assume a fixed three-layer network structure of an ID. Nodes that correspond to threats are placed in the top layer. The middle layer of the network always includes two nodes, corresponding to the direct (Capacity loss) and indirect (Demand change) impact on the TN element functionality. In the lowest layer a single utility node (Disruption rate) would be placed that would combine the effects of Capacity loss node and Demand change node. A simple example of the ID model is shown in Figure 2.

A lot of different research approaches related to the resilience assessment are based on the subject matter experts (SMEs) (represent by relevant stakeholders) opinions, consultations, or evaluations [e.g. 48-49]. Involving the SMEs into several steps within the IDs modelling is assumed. In the first step of modelling, a list of possible threats should be produced. This can be done by the SMEs familiar with given TN and with the concept of risk assessment, or by selection of pre-defined threats, which are of particular interest. Threats are assumed to be binary (present or absent) and quantified by asking the SMEs to provide probability of the threat occurring.

It is argued, as some authors [50-51], that a system might be vulnerable to certain events but be resilient to 
Table 4 An example of definition for the utility node - Disruption rate

\begin{tabular}{|c|c|c|c|c|}
\hline \multirow{2}{*}{ Capacity } & \multicolumn{4}{|c|}{ Demand } \\
\hline & Lowered & Normal & Increased & Mass Evacuation \\
\hline Nominal & 0 & 0 & 0.2 & 0.7 \\
\hline Low Operability Limitation & 0.05 & 0.25 & 0.5 & 0.8 \\
\hline Significant Operability Limitation & 0.5 & 0.7 & 0.8 & 0.9 \\
\hline Partial Collapse & 1 & 1 & 1 & 1 \\
\hline Total Collapse & 1 & 1 & 1 & 1 \\
\hline
\end{tabular}

others. Therefore, it is important to take into account the specific risk and threat profiles to the area under analysis. Moreover, the occurrence of multiple events at once is highly unlikely, of course, if one omits the possibility of a synergic effect; e.g. occurrence of the earthquake and flood at the same time is very unlikely, but combination of a snowstorm and a traffic accident is very likely. From that reason it is assumed that each threat is assessed separately and in the relevant cases combination of the two threats is assumed. That is also dictated by practical considerations, while the burden placed on the SMEs providing probabilities should be limited. In particular, nodes with a large number of parent nodes (a large number of incoming links) should be quantified with a number of exponential probability distributions. This implies that if there are 5 parent nodes (5 threats) to a node (e.g. Capacity loss node) and all of them are binary (have only two states), an SME would be required to provide $2^{5}=32$ probability distributions, what would be hardly feasible in practice.

Next step is to designate if the threat has a potential to directly affect a TN element, i.e. to block, damage or destroy road surface, etc. The SMEs would need to provide corresponding probabilities. Similarly, the SMEs would need to define if the threat can result in increased (even mass evacuation) or decreased traffic - if the demand on the TN element can be affected and provide corresponding probabilities. The states of the nodes would be as mentioned above: Nominal, Low Operability Limitation, Significant Operability Limitation, Partial Collapse and Total Collapse for the Capacity loss node and Lowered, Normal, Increased and Mass Evacuation for the Demand change node. Examples of Capacity loss node and Demand change node are illustrated in Tables 2 and 3.

As it is shown in Tables 2 and 3, there are significant differences in definition of both nodes. In order to reduce the number of parameters required to specify the ID model and properly capture relevant interactions between the variables, it is decided to set at least the Demand change node as the noisy-average node, which is available in GeNIe software and allows reducing the number of parameters required to quantify the model from exponential to linear in the number of parent nodes (the Capacity loss node does not meet the required conditions for noisy-average node because a threat cannot increased the capacity of the TN element, it can only decrease its capacity - see following conditions). The noisy-average nodes are suitable for the modelled interactions between variables (nodes) where the following conditions are met [46]: (1) the parent nodes have a state that describes the 'normal' state (there is no snowstorm, no flood, etc.), (2) the child node has a 'normal' state, as well (corresponding to typical traffic patterns or the level of traffic flow for which the road was designed), (3) for the child variable the deviation from the 'normal' state can be in both increased and decreased values. The way the influences are combined is achieved by averaging (hence the name), which means that no single parent variable is assumed to have stronger influence on the state of the child variable than the other parent variables.

The last step is to combine the direct and indirect impact of the threat(s) on the TN element functionality. The utility node (Disruption rate) merging the Capacity loss and Demand change can be defined as it is shown in Figure 2. The probability values are again required to be produced by the SMEs (e.g. in Table 4).

\subsubsection{Calculation of the disruption rate}

In order to understand how the approach works, an example of the ID model is considered that assumes 3 different threats: Traffic Accident, Wind Storm and Chemical Release. As it is shown in Figure 2, the three options are considered by which a threat can affect the child nodes (second level/layer):

- a threat can affect only the capacity of the TN element, e.g. a Traffic Accident has a potential to affect capacity of the TN element, but it does not produce a demand on a system;

- a threat can affect only the Demand, e.g. an incident associated with the release of chemical substance (Chemical Release) can result in forcing people to leave the threatened area (some form of evacuation) and incur heavy load on the TN, but it is assumed that the infrastructure is able to withstand such a release with no noticeable effects on it;

- a threat such as Wind Storm can affect both variables, Capacity as well as Demand, because there is a chance that some transportation links could be blocked or damaged due to trees or other obstacles and there is still a possible change in demand, in both directions, increased if evacuation is needed or decreased if people will be afraid of using the $\mathrm{TN}$ in such weather conditions and at the same time they will feel safe at the current position (home, work, etc.). 


\begin{tabular}{|l|}
\hline \multicolumn{2}{|l|}{ Traffic_Accident } \\
\hline Present $1.000 \%$ \\
Absent $99.000 \%$
\end{tabular}

Figure 3 Probability of a traffic accident occurrence

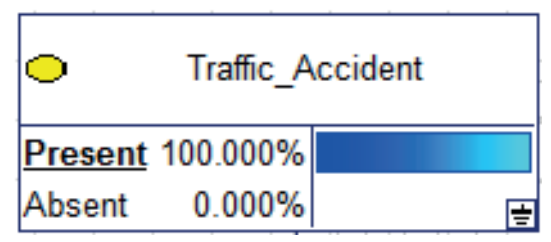

Figure 4 The instantiated node - traffic accident is present

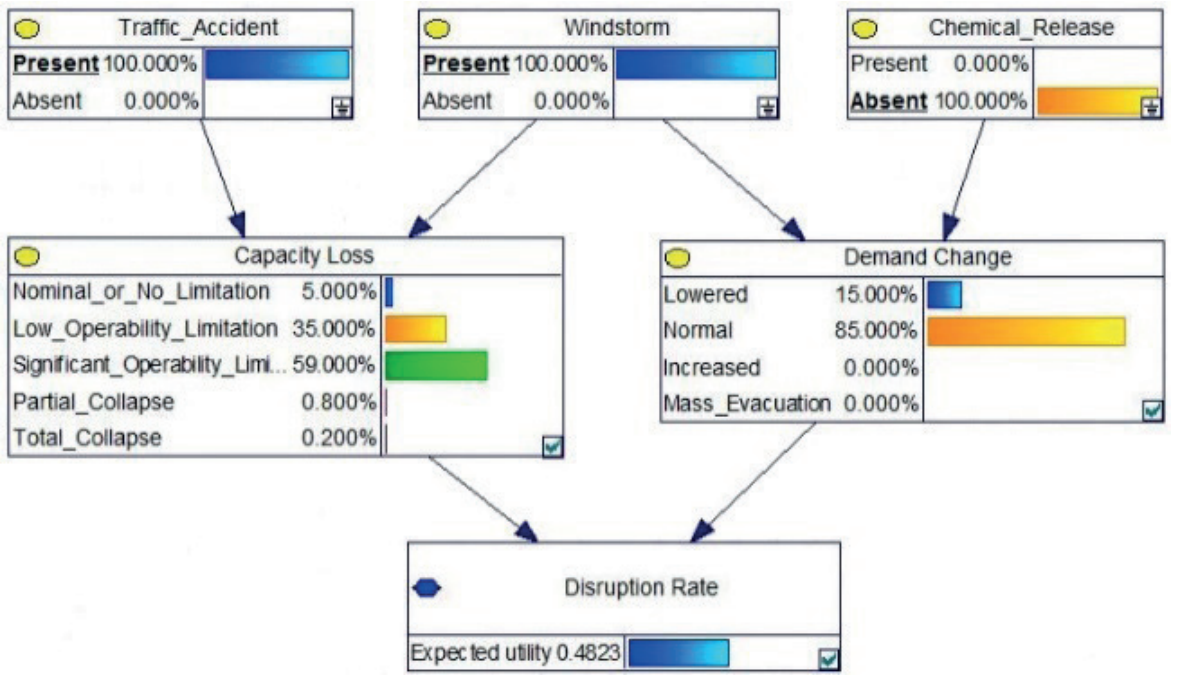

a)

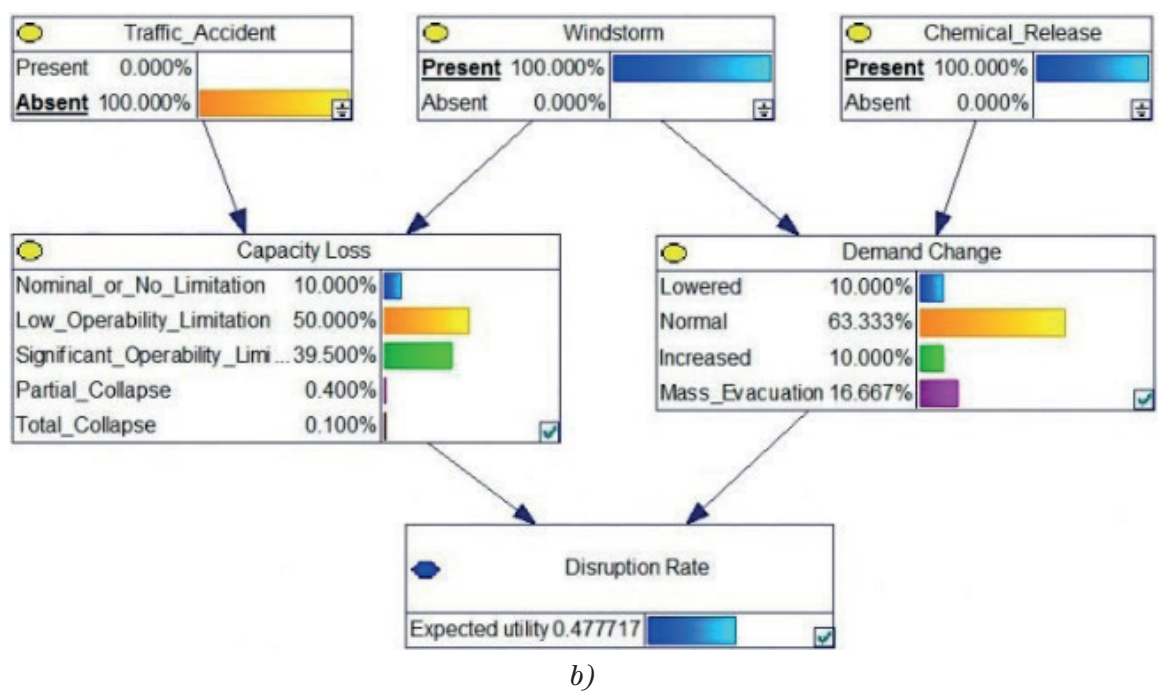

Figure 5 The ID model for calculation of the Disruption rate for two (present) threats combination

For each threat corresponding probabilities of occurrence are provided: e.g. Traffic Accident: 0.01, Wind Storm: 0.001, Chemical Release: $10^{-5}$. In order to calculate resilience to certain events (threats) the idea that some of the events should be considered as "present" is implied, rather than to calculate with probability of their occurrence. This is dictated by the interest to assess the resilience of the TN element "when" a threat occurs rather than "if" it occurs. Using of the IDs allow for such a dynamic calculation (see example of difference in Figure 3 - probability of occurrence; and Figure 4 - the instantiated node - traffic accident is present) which can be consider as the IDs benefit. The same setting option is available for the second layer as well, e.g. it is possible to set a state of Demand change node to Mass Evacuation or to set a state of Capacity loss node to Partial Collapse, etc.

For the sake of an example, the two cases are analyzed: (1) combination of present threats Traffic Accident and Wind Storm at the same time (Figure 5a); (2) combination of present threats Wind Storm and Chemical Release at the same time (Figure 5b).

Following the values from Table 4, in the Disruption rate node will show up the probabilistic dependencies of child nodes and parent nodes, by means of conditional probabilities, so expected values will vary based on the probabilities of the child nodes. The expected utility value 


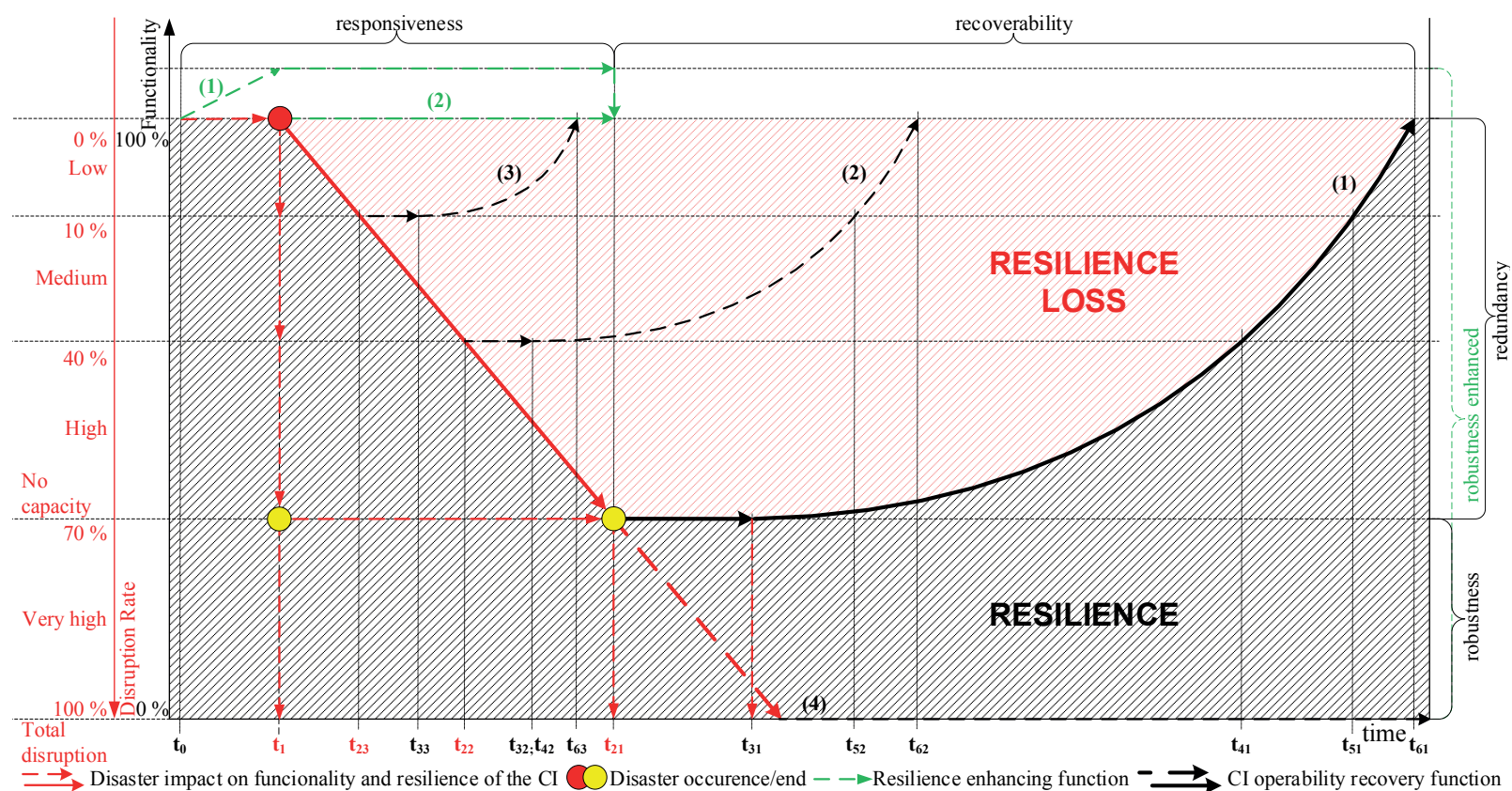

Figure 6 The time decomposition of a CI element disruption profile in relation to overcoming its resilience

of the Disruption rate node reflects the potential impact of an extraordinary event on the functionality of the TN element, considering only its robustness and partially absorption capacity. It does not reflect other resilience features. Therefore these features are included into resilience assessment separately and within the Disruption duration part.

\subsection{Disruption duration - time decomposition of the CI element functionality disruption}

Except for the extent of a TN element disruption, the time aspect related to that disruption is necessary to take into consideration [52], since with increasing duration of the disruption, resilience is lower [34]. Globally, the time aspect of a TN element resilience, in this case called the Disruption duration, will vary based on resilience features. A broad measure of the TN elements resilience which captures influence of those resilience key features and their relation to a TN element functionality can be expressed in form of the time decomposition profile illustrated in Figure 8 . Basically, there are two resilience features, responsiveness and recoverability, that directly express disruption duration of a TN element. In most cases, the disruption duration of a TN element functionality is the same as the time needed to the recover element functionality. Therefore, the recovery activities decomposition towards the overall renewal of the TN element will be introduced as the most important part of Disruption duration. Of course, in cases where there is a gradual loss of functionality over disaster impact, we will also consider that time as a part of overall resilience loss assessment

Figure 1 also shows the connection between the robustness (partially also redundancy) and the possible functionality loss (explained in section 3.1. Disruption rate), where the loss of the robustness means the loss of the functionality. From the time perspective, the dependencies are visible as well. For example, in the worst scenarios with expected great disruption of robustness (higher level of Disruption rate), the Disruption duration is expected as longer lasting and vice versa. This assumes a certain level of dependence between the Disruption rate and Disruption duration. However, there are two issues to be aware of: (1) this logic would only apply to physical damage to the element and at the same time the condition that the elements being considered are equally large (structurally similar, with similar technical conditions) must be met - this will guarantee similar robustness; (2) otherwise, in the case that only the capacity of an element is affected, the duration of the functionality reduction depends primarily on the threat, which caused the disruption - significant differences in the recovery duration after exposure to various threats (traffic accident, snow storm, wind storm, flood, etc.) are assumed. It is possible to omit the given conditions - this would imply a certain degree of the results distortion, but at the same time it will simplify the estimation of the Disruption duration.

For the better understanding of resilience loss profile (Figure 6), the following explanations of resilience features with related time periods are provided.

\subsection{Responsiveness feature in resilience concept $t_{2 n}-t_{0}$}

Responsiveness represents the capability of the system to activate the forces and means aimed at restoring the function of the system [34,53] and at prevention of a situation deterioration. It is expressed by the time 
(responsiveness period) between the occurrence of an emergency, or even before (when the event is likely to happen) and the end of degradation elimination process and consequently its renewal [36] which can be considered as an overlapping with recovery. The two main time periods within the responsiveness are assumed - "risk factors change period" and "impact period".

\section{Risk factors change period $\left(t_{1}-t_{0}\right)$}

Risk factors change period and the whole responsiveness period are closely interconnected and will therefore be continuously explained. Continuous monitoring of internal and external environment development supports identification of changes that could have an undesirable effect on the system functions or processes in time. Early and proper assessment of risks or risk factors change is a prerequisite for taking adequate measures to increase the level of system resilience to such effects. The process of monitoring and evaluating changes of risk factors can be carried out together with (or even rather before) a possible response to both foreseeable and accidental crises. Responsiveness is therefore dependent on the prevention measures, preparedness level of the responsible authorities, rescue forces and availability of resources in order to address the crisis.

\section{Impact period $=t_{2 n}-t_{1} ; t_{2 n}-t_{0}$}

Impact period can be characterised as the time period during which the devastating and destructive features of disaster are manifested and absorption ability of a TN element is exceeded. The result is different degree of functionality loss (red arrows in Figure 6.). Depending on the exposure rate, intensity of a disaster and vulnerability of a particular TN element, two types of functionality loss can be distinguished: (1) immediate and (2) continuous.

- immediate loss of functionality - change of risk factors is rapid ( $t_{1}-t_{0}$ can be technically 0 ) and often unforeseeable. In a very short time, the effects of a disaster will be present - the consequences are immediate. There is very little time to take measures to reduce the consequences before disaster. As a result, various levels of functional impairment of the TN element may occur (Disruption Rate levels) - depending on the intensity of a disaster (shown by the red vertical dashed function). In such cases, responsiveness is very limited. Rapid loss of resilience can be observed.

- continuous loss of functionality - mostly related to a known threat resulting into a disaster with cumulative impact over a longer time period (cumulative high precipitation resulting into a continuous flood) or with progressive intensity development (wind storm with increasing speed over time). It is possible to take preventive measures (green vectors) and temporary increase the level of infrastructure resilience (enhance robustness feature or redundancy). Measures can be taken also during a disaster impact period $\left(\mathrm{t}_{2 \mathrm{n}}\right.$ $t_{1}$ ) - there is a time to respond depending on the capability of rescue services and available resources.
Such events can be predicted to a certain extent. Important elements, such as the CI elements, can be better protected.

As it was mentioned before, on the graph (Figure $6)$, possible positive changes (green vectors (1) and (2)) are also shown as an option to increase the TN element resilience level. It can be done by (a) enhancing robustness of an element (e.g. dams building against flood, adjustment of nearby surroundings, etc.); (b) enhancing redundancy of an element (e.g. prepare a plan for makeshift bridge placement and building); (c) enhancing resourcefulness - all mentioned and other actions require provision of necessary material and human resources. In order to realise such an action and use adequate resources before disaster occurs, crisis and disaster planning and procedures are required to be in place (related mainly to CI element protection). In order to facilitate subsequent recovery actions, these measures and actions may be very helpful mainly in the worst case scenarios represented by black function (3) and (2), slightly less in recovery function (1).

\subsection{Recoverability feature in resilience concept $\mathbf{t}_{6}-\mathbf{t}_{2}$}

The impact period is continuously followed by the recovery activities. There can be observed an overlapping of impact period with recovery period (phase) as the reaction on an emergency (saving and protecting people, property, environment, etc.) running in parallel with some recovery actions. See for example period $t_{21}-t_{1}$ followed by $t_{31}-t_{21}$ where is difficult to set exact end of reaction and start of the recovery phase. It will vary based on a threat severity and suddenness.

The recovery period is divided into several basic steps. In practice, there can be more stages (steps) within the recovery phase, however, in order to generalize assessment for purposes of resilience measurement, these steps can be considered as valid for almost all the scenarios of recovery.

\section{Assessment and preparatory period $=t_{3 n}-t_{2}$}

Period of aftermath assessment and preparatory measures related to the designation of recovery method (restoration of traffic flow, transport capacity, detour, etc.). Disruption rate level remains the same. A lower level of disruption requires a shorter assessment time as the assessment activities are easier. In the worst cases the preparatory period can be as long as preparation of project documents and selection of a contractor. The result of the assessment can be (in the time $t_{31}$ ) a rejection of any recovery efforts as well, due to high recovery expenses or due to extensive structural damage.

\section{Temporary recovery $=t_{4 n}-t_{3 n}$}

The period during which the aim is to restore the transport operability as quickly as possible. Use of the provisional measures is assumed. This phase is designated to achieve the required level of the performance (reduce the 


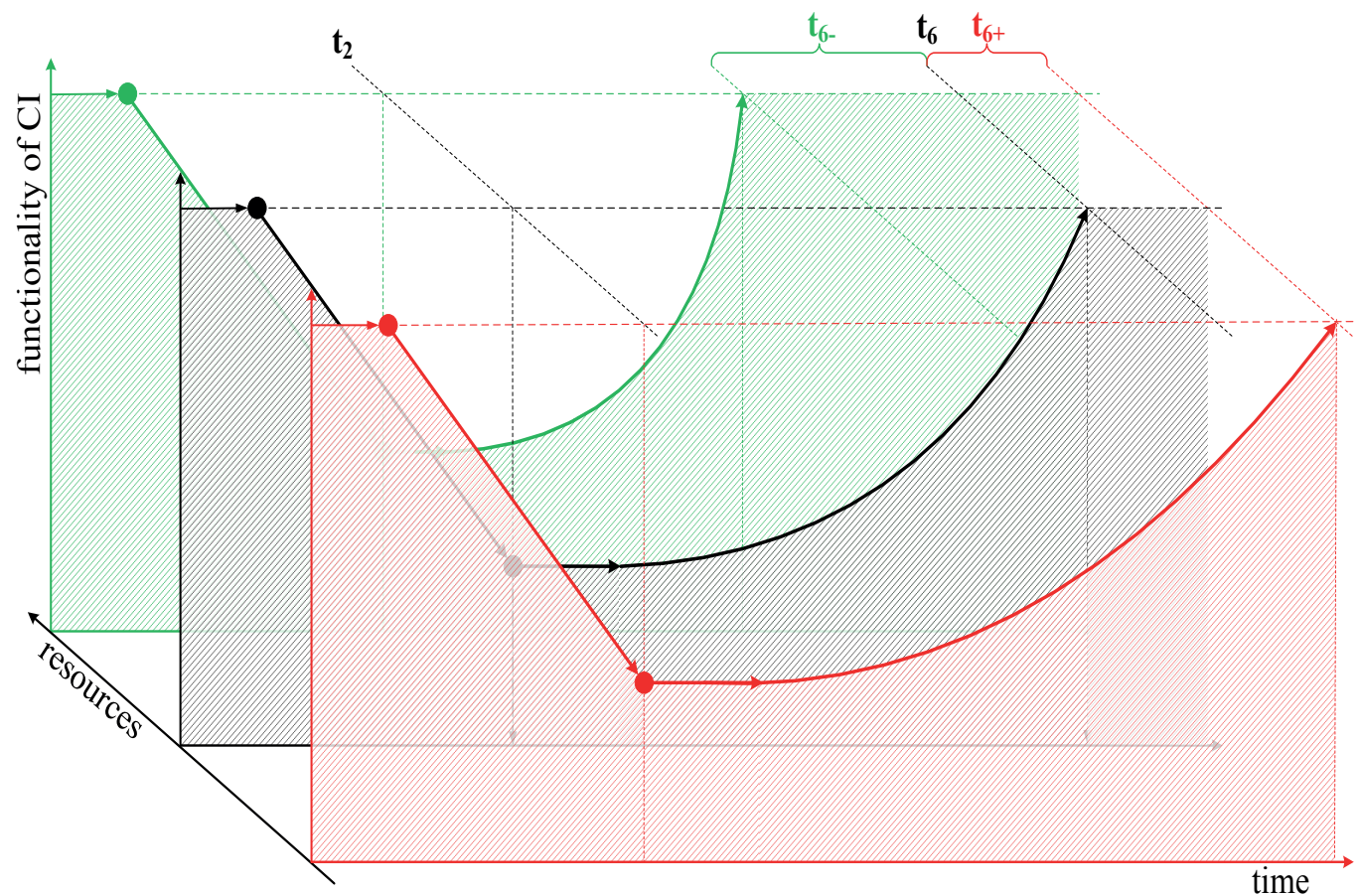

Figure 7 Possible influence of the resourcefulness on the recovery time and the resilience of the CI (adapted from [32])

loss of a TN element capacity). As the assumed elements are the CI elements, the common transport capacity is expected to be high and therefore achieving of the required level of performance will be more demanding. Described type of recovery is designated mainly for cases of the high transport capacity loss or in the case of malfunction.

This temporary recovery should bring the TN element into the better state but there still would remain some degree of disruption. For purposes of further calculation, this disruption state will be marked as $D R_{T R}$.

If the transport capacity of the TN element is affected, more resilient elements will be more redundant and another routes will be available to address demand on affected element. It should be stated that the estimated start of the recovery activities is immediate (in Figure 8), however, in practice it may take much more time due to preparation of the documents, inadequate policies or ineffective procedures in the preparatory phase.

\section{Partial recovery $=t_{5 n}-t_{4 n}$}

All the construction and technical deficiencies or operational obstacles must be removed during this period in order to achieve the full transport capacity. It must be achieved at a higher operating speed (e.g. for rail transport at least $60 \mathrm{~km} \cdot \mathrm{h}^{-1}$ ) but some limitations are still in place.

Similarly, partial recovery should bring the TN element into the better state but there still would be some degree of disruption. For purposes of further calculation, this disruption state will be marked as $D R_{P R}$

\section{Full recovery $=\mathbf{t}_{6 \mathrm{n}}-\mathbf{t}_{5 \mathrm{n}}$}

The TN element functionality is recovered without operation limitation with full transport capacity and with the designed maximum permissible speed.

\subsection{Resourcefulness feature in resilience concept}

As it was mentioned, the time necessary for keeping or restoring the functionality of the CI element is dependent on the organisational preparedness of the crisis management (crisis planning, recovery planning, policies in place, etc.). It is represented by the features responsiveness and recoverability. Implementation of prepared procedures and approaches is conditioned by resources (material as well as human resources), which we are at disposal in order to manage the impacts of a disaster. It can be illustrated by the resilience expansion into three-dimension level (Figure 7).

By appropriate allocation and use of resources, the CI functionality loss time $\left(\mathrm{t}_{6}\right)$ can be reduced. The time may be reduced in period of the "impacts", as well as in "assessment" period and in all the "recovery" periods. Theoretically, if infinite resources were available, time to recovery would asymptotically approach zero [39]. If the necessary resources are not available, the time of the operability loss can increased $\left(t_{6+}\right)$. Resourcefulness and responsiveness (and recoverability) can be seen as the complementary features because without appropriate resources in place, it is impossible to react accordingly, but even if the amount of resources was sufficient, the response or recovery time may be longer due to human limitations, missing or neglected planning, inadequate procedures, operational and organizational failures or ineffective policies [39].

To quantify and mathematically describe resourcefulness some variable can be used, as it is in [39]. 


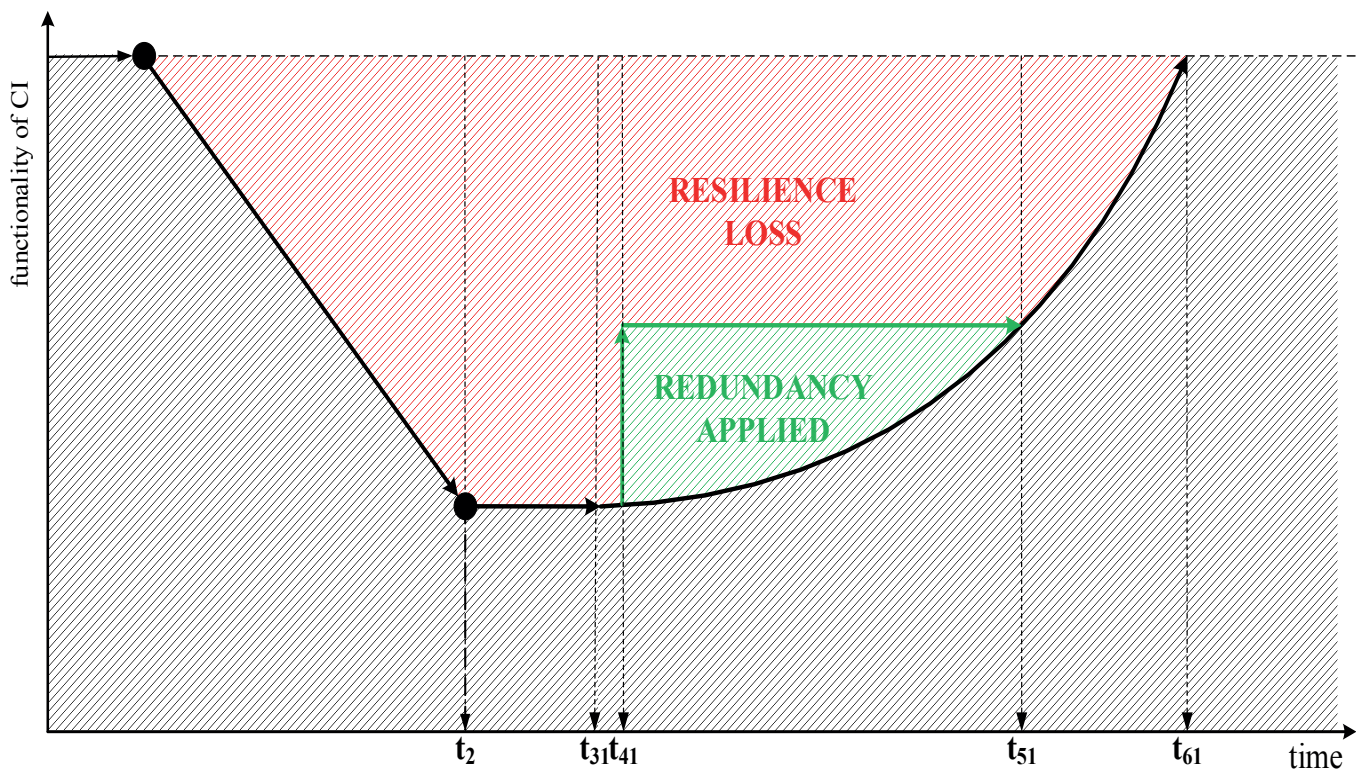

Figure 8 Redundancy feature applied in resilience concept

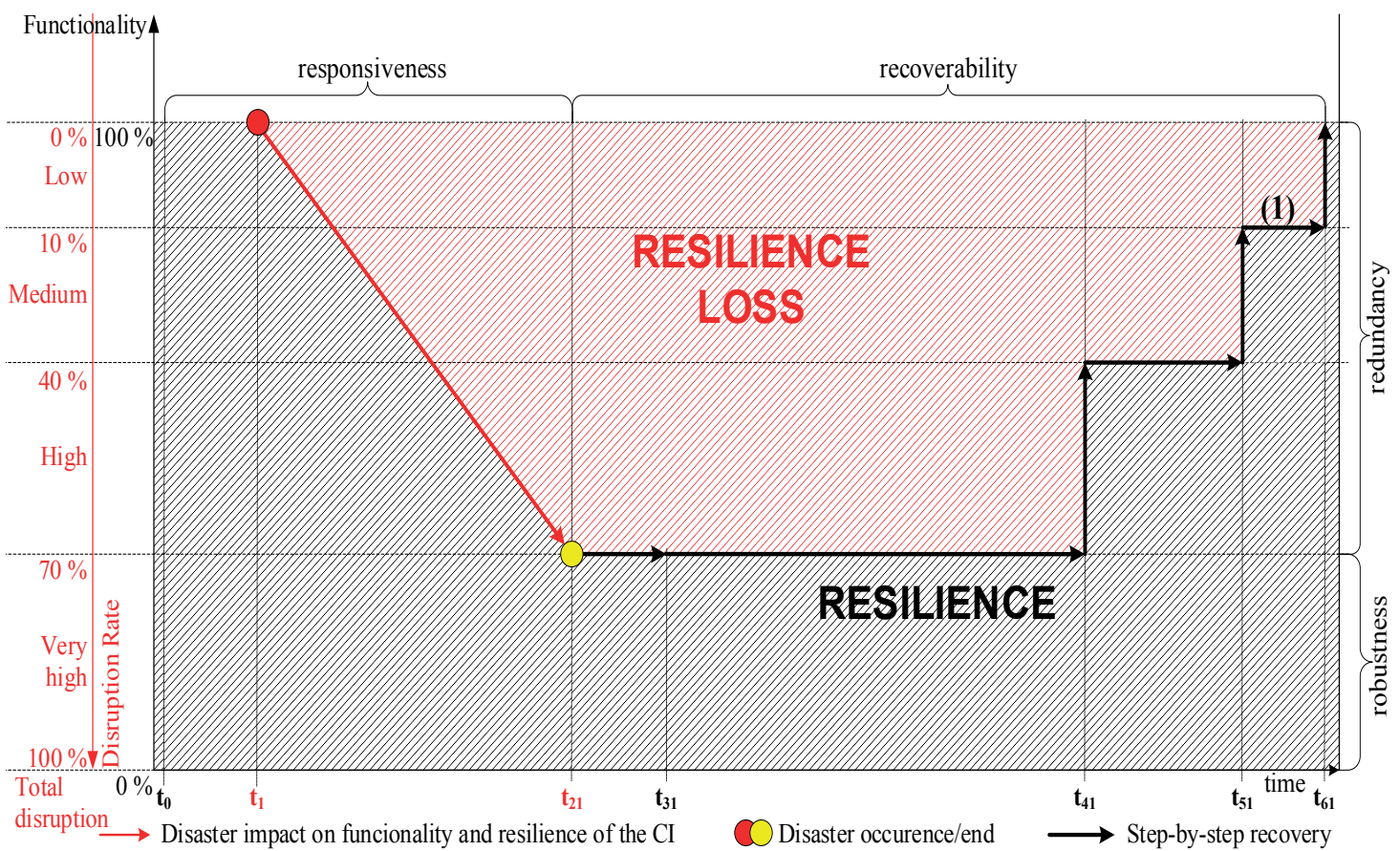

Figure 9 Resilience profile; step-by-step recovery periods applied

\subsection{Redundancy feature in resilience concept}

The TN element is redundant if it can be replaced, for example, a temporary bridge, which replaces a broken one until it is repaired (Figure 8 - green shaded area). However, it is more common in electrical networks, where, for example, in the case of a generator failure, a second one will be ready to replace it immediately. Replacement of individual TN element is not so flexible and therefore more common is use of the TN network redundancy rather than redundancy of a particular TN element. In this case, one can understand redundancy of a TN element as its possible substitution by another element or set of elements within the network - they provide connection to the original destination. This case is addressed within Demand change part, which has already been explained in subsection 3.1.2. The problem arises if such an alternative does not exist or an alternative fails to fully satisfy the demand, or only with great constraints - redundancy is very low or there is no redundancy.

According to Figure 8 redundancy does not shorten the time needed for reparation or rebuilding but it helps the network to reduce the demand for a damaged element. If such resources are at disposal to temporary cope with impacts of disaster on particular element, one can significantly reduce the functionality loss, as well as the resilience loss. 


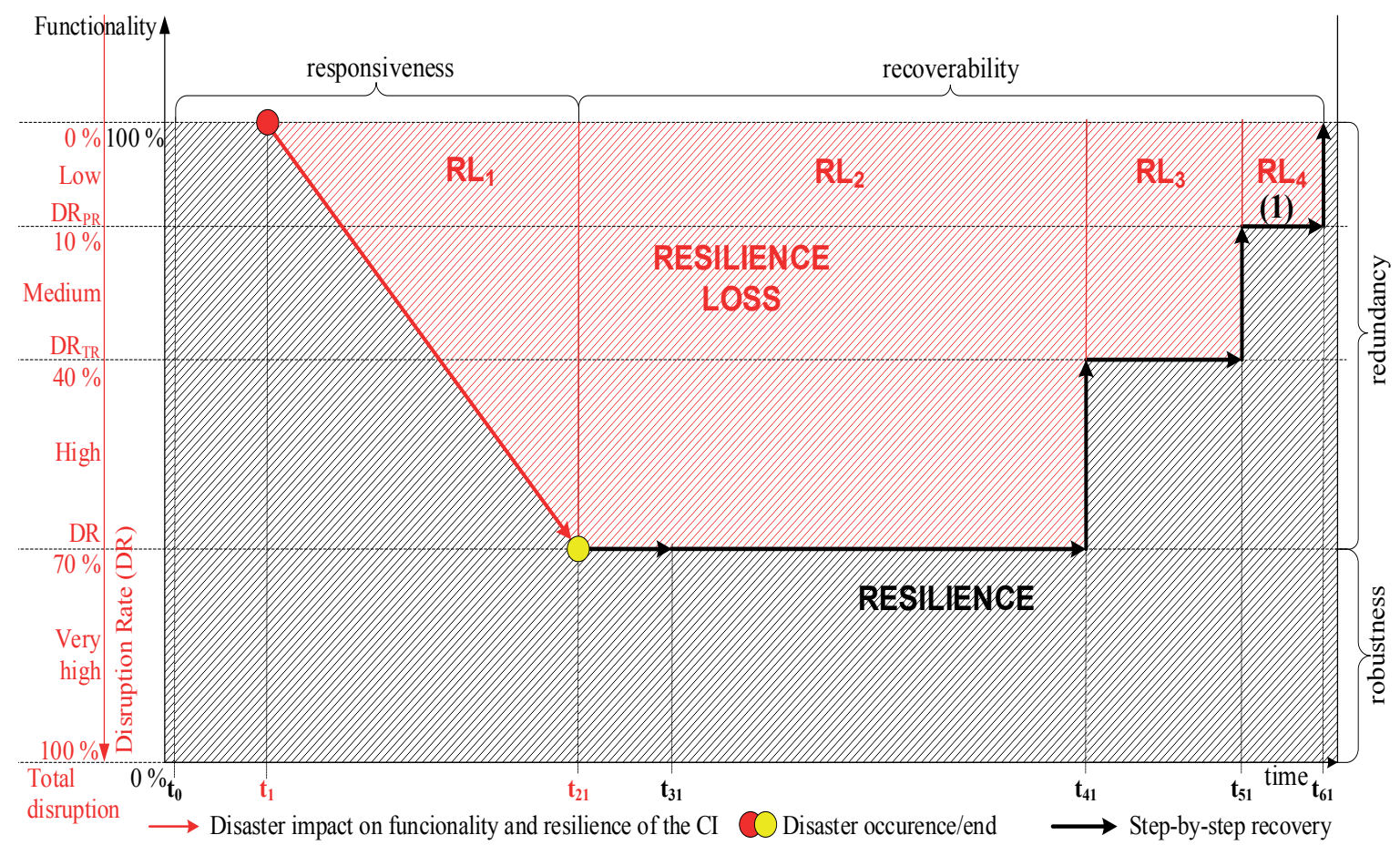

Figure 10 Resilience profile divided into several parts (for the purpose of calculation)

\subsection{Implementation particularities of transportation system into the resilience assessment concept}

Regarding to literature, the authors predominately use the option of continuous recovery function over time for different system under analysis [34, 37, 41, 44]. Here is adopted the idea that recovery of the TN functionality, or its part, or an element in particular, is in practice implemented by completing of different recovery stages, step by step (level by level) rather than continuously. For example, after damages on the road, repairing of one road lane is in progress, so the performance of such an element is let say $50 \%$. When that lane is repaired and no further work is required, then the performance is at some point again $100 \%$. There is no gradual rise from $50 \%$ to $100 \%$ but "a jump" from $50 \%$ to $100 \%$. From this reason, for understanding and measurement of the recovery process duration, as well as for assessment of the resilience loss, a more suitable disruption and recovery decomposition is illustrated in Figure 9 (similarly used in [54]). Three different levels of recovery, corresponding to three defined recovery periods (plus an assessment period) are taken into consideration (see section 3.4). It is argued here that this particularity of transportation system applies for the majority of the disruption cases and it also simplifies the final calculation of the resilience loss.

Unlike the case in Figure 6, the concept illustrated in Figure 9 requires an assessment of individual recovery periods because one needs to estimate the time frame e.g. from $t_{31}$ to $t_{41}$. Since the resilience assessment is conducted in the safety state, only an estimate can be made. It can be based on evidence of events that have already happened or on qualified experts' estimates.

\section{Results - the measure of the critical infrastructure resilience}

As it was mentioned, it is preferred to assess the resilience of the TN element by expressing its loss rate over time (resilience loss - $R L(t)$ ). The measure of a TN element resilience loss can be expressed in more detailed way using Figure 10, which divides RL into several parts $\left(\mathrm{RL}_{1}, \mathrm{RL}_{2}\right.$, $\mathrm{RL}_{3}, \mathrm{RL}_{4}$.

Mathematically, RL can be defined as a sum of these individual parts within the response and recovery phases:

Resilience Loss $=R L_{1}+R L_{2}+R L_{3}+R L_{4}$,

In more detailed way:

Resilience Loss $=\frac{1}{2} \int_{t_{1}}^{t_{21}} D R(t) d t+$
$+\int_{t_{21}}^{t_{41}} D R(t) d t+\int_{t_{41}}^{t_{51}} D R(t) d t+\int_{t_{51}}^{t_{61}} D R(t) d t$,

where:

$\mathrm{DR}(\mathrm{t})=$ calculated Disruption rate,

$\mathrm{DR}_{\mathrm{TR}}(\mathrm{t})=$ designated Disruption rate after temporary recovery (in this case it is set on $40 \%$ ),

$\mathrm{DR}_{\mathrm{PR}}(\mathrm{t})=$ designated Disruption rate after partial recovery (in this case it is set on 10\%).

Basically, the first part of Equation 3 means the expected balance in quality during the disaster impact $\left(t_{21}-t_{1}\right)$, the second part is the expected balance during the 
assessment period $\left(t_{31}-t_{21}\right)$ and temporary recovery $\left(t_{41}-t_{31}\right)$, the third part is the expected balance in quality over the time to partial recovery $\left(\mathrm{t}_{51}-\mathrm{t}_{41}\right)$ and the fourth part is the expected balance in quality over the time to full recovery $\left(t_{61}-t_{51}\right)$. The given equation defines the concrete example illustrated in Figure 12. We claim that it will be different for each disaster, since the intensity of a threat and recovery options will vary from case to case.

\section{Discussion}

Based on definition, Figure 10 illustration and calculation (Equation 3) of the resilience loss, it can be assumed that similar shaded areas would correspond to the same resilience loss. For instance, Figure 11 parts (A) and (B) represent the same resilience loss, however, in the case (A) the loss of performance provided is not significant but it takes considerably longer time as it is in the case (B). On the contrary, in the case (B), the loss of the performance is more severe, but a TN element will recover faster (e.g. trees of the road). It seems that different levels of functionality loss could be a case for some infrastructural networks [39], as well as for the transport critical infrastructure.

As it was mentioned before, it is preferred to use the resilience loss profile for the $\mathrm{TN}$ elements assessment illustrated in Figure 10. For the purpose of this discussion section, it is represented by Figure 12.

The question is, what is for a user or assessor considered to be a more important disruption: (1) a less disruption that takes longer time and affects a greater number of people (Figure 12A), or (2) a more serious disruption that takes less time and affects probably less people (see Figure 12B). Assuming that with increasing functionality loss, the time needed to remove this disruption will increase, the problem would be practically solved, since example $\mathrm{B}$ would be impossible. However, there are situations where there this assumption does not apply, such as a traffic accident that can block (full disruption) traffic for a few hours, but after that, a disrupted link will be fully

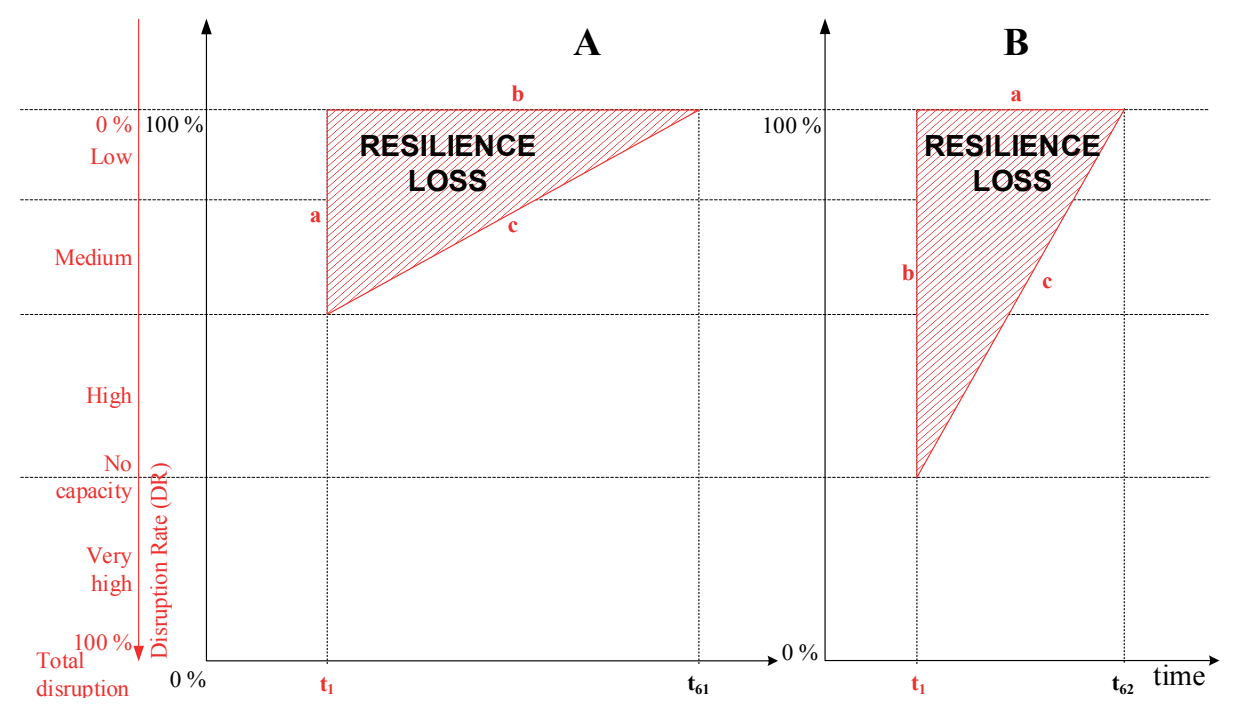

Figure 11 Difference in resilience loss (gradual restoration of functionality assumed)

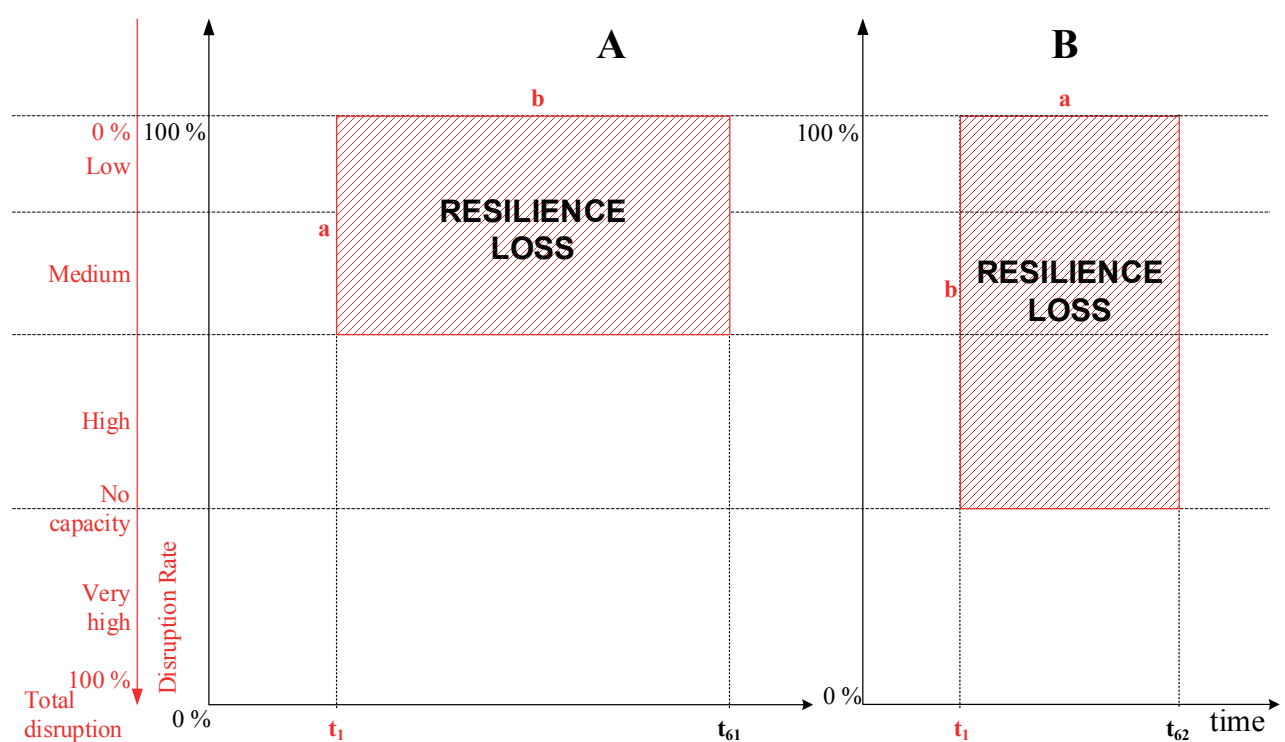

Figure 12 Difference in resilience loss (instant restoration of functionality assumed) 


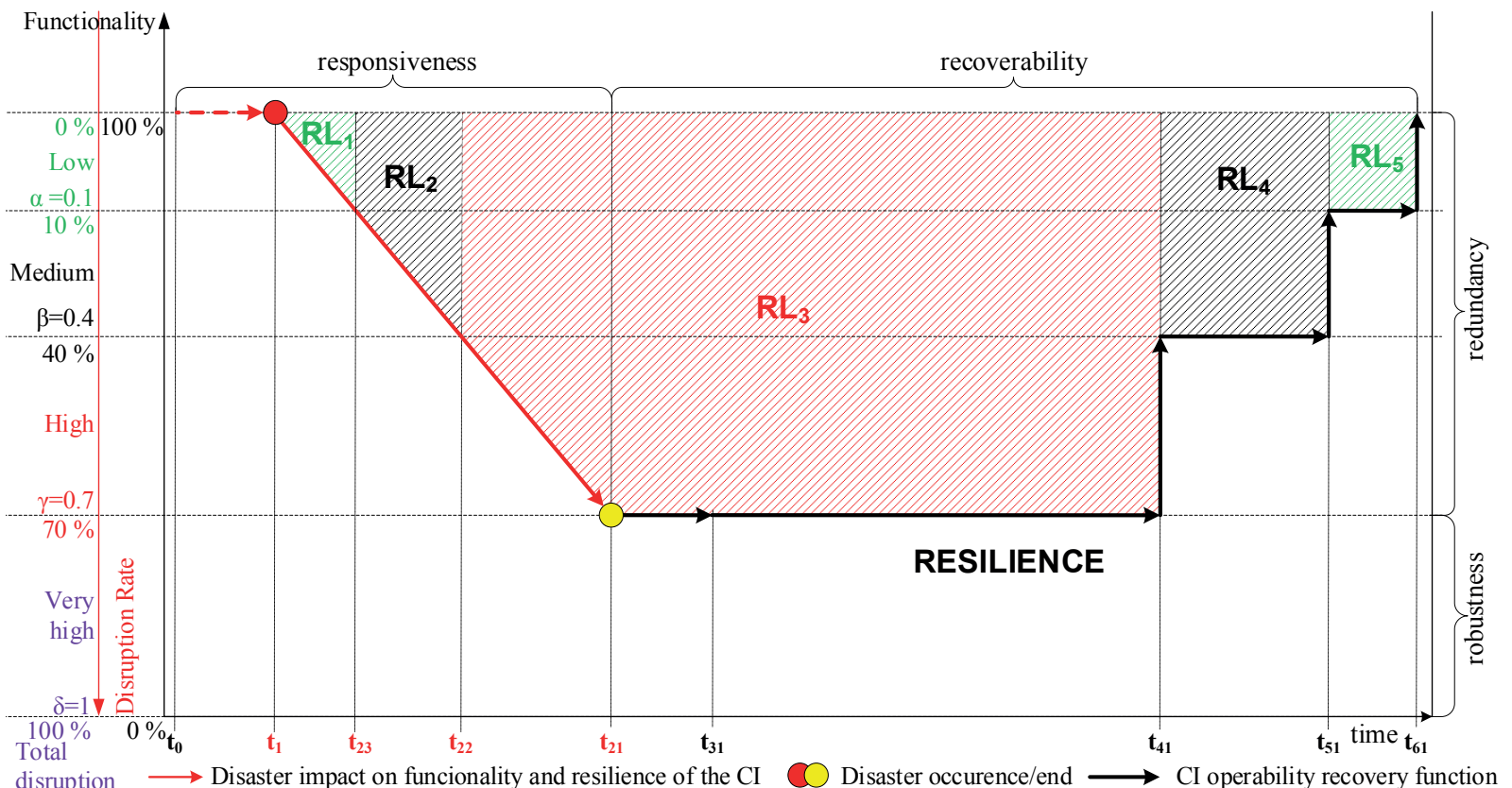

Figure 13 Differences in disruption importance for the resilience calculation

operable again. In order to capture these differences, use of the weighted values (e.g. $\alpha, \beta, \gamma, \delta$ ) for different levels of resilience loss is assumed, rather than performing the consequences analysis for different scenarios of disruption. With increasing Disruption rate the higher importance (higher weight value) is assumed.

To illustrate these differences in disruption importance, Figure 13 is used as an example.

In this example are used the following weights: $\alpha=0.1 ; \beta=0.4 ; \gamma=0.7 ; \delta=1$. Given weights are the same for the impact period, as well as for the recovery period (they correspond to temporary recovery level $\mathrm{DR}_{\mathrm{TR}}$ and partial recovery level $\mathrm{DR}_{\mathrm{PR}}$ ). They can vary based on the assessor's preferences, but they should be consistent for all TN elements under analysis. Given assumptions also change the calculation of Resilience Loss final value (Equation 4):

Resilience Loss $=\alpha R L_{1}+\beta R L_{2}+\gamma R L_{3}+$ $+\beta R L_{4}+\alpha R L_{5}$

As can be seen, the weight $\alpha$ is assigned to the green areas with low disruption of TN element functionality; similarly $\beta$ is assigned for the medium disruption rate and so on. The weight $\delta$ is not used in this particular example, but it will be used if disruption rate (DR) of value more than 0.7 is predicted. The calculation could vary if e.g. immediate loss of the functionality is assumed $\left(t_{21}-t_{1}=0\right)$.

The importance of different disruption levels, thus addresses, implies some degree of the results distortion, but if the approach and assessment are used consistently for all the network elements (or designated network part), the values can be comparable and useful in the context of the whole network.

\section{Conclusions}

The concept of resilience in the context of transportation network is a subject of active interest from both practitioners' and academic communities. There is a number of definitions and different understandings of resilience in transport, as well as a number of methodologies to evaluate resilience. Those methodologies need a huge number of properties and large processes to be performed to get results and this fact can be a disadvantage [41]. From that reason a proposed approach is intended to be applied to the CI elements, rather than to the transportation network as a whole. This is also dictated by the practical considerations, while burden placed on the assessors should be limited.

This paper provides an approach to the resilience measurement by expressing resilience loss. The approach is based on the IDs, which was used as a tool to model functionality disruption level (Disruption rate) and it was combined by duration of disruption (Disruption duration). The probabilistic definition of Disruption rate level used in IDs is the most important part of the assessment. It allows for quantitative expression of disruption level based on the conditional probability of variables in modelled domain. Since besides the commonly considered variable "performance loss" or disruption (called the capacity loss), a new very important variable for TN (demand change) into model is added, the IDs are very appropriate in modelling these relationships. The combination of these two properties in IDs benefits into more accurate expressing of overall resilience loss than in other approaches. It results into identifying of more and less resilient $\mathrm{TN}$ elements, which can be compared and appropriate measures can be made to increase the overall resilience of the particular $\mathrm{TN}$ element. It can be done for the all resilience features 
(robustness, redundancy, resourcefulness, responsiveness, recoverability). There are also several other benefits resulting from using the IDs: (1) it allows for more compact and efficient knowledge elicitation, (2) it allows for dynamic assessment of resilience, under assumption that some of the events are observed (some nodes will be instantiated in ID) - for example if there is wind storm in area, the model can result with increased Distortion rate for some elements, allowing for implementing measures that would provide situational awareness, (3) it reduces burden placed on the assessors

As a result, the resilience loss profile and calculation of the resilience loss are introduced. Unlike in other approaches, it is argued that within the $\mathrm{TN}$ it is more appropriate to model and calculate recovery in a form of several separate "step-by-step" activities, rather than as a continuous (e.g. linear) function of a single recovery activity. Moreover, the disruption levels importance, in form of weights, is also discussed as an important part of an accurate resilience loss assessment.

This research indicates that understanding of the resilience distribution in the transportation network may help to identify critical components of transportation infrastructure, make the transportation infrastructure less vulnerable to effects of disasters and adopt soft or hard measures in order to enhance the resilience of transportation elements and resilience features in particular.

\section{References}

[1] ABUDAYYEH, D., NGODUY, D., NICHOLSON, A. Traffic signal optimisation in disrupted networks with re-routing. Transportation Research Procedia [online]. 2018, 34, p.195-202. ISSN 2352-1465. Available from: https://doi.org/10.1016/j.trpro.2018.11.032

[2] BURWELL, D. An exchange of building U.S. road capacity: metropolitan transportation politics. In: Moving people, goods and information in the $21^{\text {st }}$ century. The cutting-edge infrastructures of networked cities. HANLEY, R. E. (ed.). London and New York: Reutledge Taylor and Francis Group, 2004, p.127-137.

[3] Vyskumny ustav dopravny / Research Institute of Transport. Analyza rizik sektora doprava, podsektory cestna doprava a zeleznicna doprava / Risk analysis of the transport sector, subsectors of road transport and rail transport (in Slovak). Zilina, 2014.

[4] KAHN RIBEIRO, S., KOBAYASHI, S., BEUTHE, M., GASCA, J., GREENE, D., LEE, D. S., MUROMACHI, Y., NEWTON, P. J., PLOTKIN, S., SPERLING, D., WIT, R., ZHOU, P. J. Transport and its infrastructure. In: Climate change 200\%: Mitigation. Contribution of working group III to the fourth assessment report of the intergovernmental panel on climate change. METZ, B., DAVIDSON, O. R., BOSCH, P.R., DAVE, R., MEYER L. A. (eds.). Cambridge University Press, 2007.

[5] SIMAK, L., DVORAK, Z., GASPIERIK, L., KAMPOVA, K., REITSPIS, J., SEIDL, M., SVETLIK, J. Protection of critical infrastructure in sector transportation. Zilina: EDIS, 2012.

[6] LEITNER, B., LUSKOVA, M., O'CONNOR, A., VAN GELDER, P. Quantification of impacts on the transport serviceability at the loss of functionality of significant road infrastructure objects. Communications - Scientific Letters of the University of Zilina [online]. 2015, 17(1), p. 52-60. ISBN 1335-4205, eISSN 2585-7878. Available from: http://komunikacie.uniza.sk/index.php/communications/article/view/393

[7] TAYLOR, M. A. P, D'ESTE, G. M. Concepts of network vulnerability and applications to the identification of critical elements of transport infrastructure. 26th Australasian Transport Research Forum : proceedings [online]. 2003. Available from: http://search.ror.unisa.edu.au/media/digital/open/9915913443501831/12143366150001831/13143375830 $001831 /$ pdf

[8] LOVECEK, T., RISTVEJ, J., SIMAK, L. Critical infrastructure protection systems effectiveness evaluation. Journal of Homeland Security and Emergency Management [online]. 2010, 7(1). eISSN 1547-7355. Available from: https://doi.org/10.2202/1547-7355.1613

[9] HOLLA, K. Lessons learned from the implementation of the SEVESO III directive in the Slovak Republic. Safety and Security Engineering VII [online]. 2018, 174, p. 25-31. eISSN 1743-3509. Available from: https://doi.org/10.2495/SAFE170031

[10] HOLLING, C. S. Resilience and stability of ecological systems. Annual Review of Ecology and Systematics [online]. 1973, 4, p.1-23. ISSN 1545-2069, eISSN 1545-2069. Available from: https://doi.org/10.1146/annurev.es.04.110173.000245

[11] DEANGELIS, D. L. Energy flow, nutrient cycling and ecosystem resilience. Ecology [online]. 1980, 61(4), p. 764-771. eISSN 1939-9170. Available from: https://doi.org/10.2307/1936746

[12] YODO, N., WANG, P. Engineering resilience quantification and system design implications: a literature survey. Journal of Mechanical Design [online]. 2016, 138(11). ISSN 1050-0472, eISSN 1528-9001. Available from: https://doi.org/10.1115/1.4034223

[13] HOFFMAN, E. Building a resilient business. Raptor Networks Technology Inc., 2007. 
[14] OMER, M., NILCHIANI, R., MOSTASHARI, A. Measuring the resilience of the transoceanic telecommunication cable system. IEEE Systems Journal [online]. 2009, 3, p. 295-303. ISSN 1932-8184, eISSN 1937-9234. Available from: https://doi.org/10.1109/JSYST.2009.2022570

[15] SAURIN, T. A., CARIM JUNIOR, G. C. Evaluation and improvement of a method for assessing hsms from the resilience engineering perspective: a case study of an electricity distributor. Safety Science [online]. 2011, 49(2), p.355-368. ISSN 0925-7535. Available from: https://doi.org/10.1016/j.ssci.2010.09.017

[16] OUYANG, M., DUENAS-OSORIO, L. Multi-dimensional hurricane resilience assessment of electric power systems. Structural Safety [online].2014, 48, p.15-24. ISSN 0167-4730. Availablefrom:https://doi.org/10.1016/j.strusafe.2014.01.001

[17] YODO, N., WANG, P. Resilience analysis for complex supply chain systems using bayesian networks. 54th AIAA Aerospace Sciences Meeting : proceedings [online]. AIAA SciTech Forum, 2016. eISBN: 978-1-62410-578-4, AIAA 2016-0474. Available from: https://doi.org/10.2514/6.2016-0474

[18] LUNA, R., BALAKRISHNAN, N., DAGLI, C. H. Post earthquake recovery of a water distribution system: discrete event simulation using colored Petri nets. Journal of Infrastructure Systems [online]. 2010, 17(1), p. 25-34. ISSN $1076-0342$. Available from: https://doi.org/10.1061/(ASCE)IS.1943-555X.0000039

[19] Cimellaro, G. P., REINHORN, A. M., BRUnEAU, M. Seismic resilience of a hospital system. Structure and Infrastructure Engineering [online]. 2010, 6(1-2), p. 127-144. ISSN 1573-2479. Available from: https://doi.org/10.1080/15732470802663847

[20] TAMVAKIS, P., XENIDIS, Y. Comparative evaluation of resilience quantification methods for infrastructure systems. Procedia-Social and Behavioral Sciences [online]. 2013, 74, p. 339-348. eISSN 1877-0428. Available from: https://doi.org/10.1016/j.sbspro.2013.03.030

[21] ALIPOUR, A., SHAFEI, B. seismic resilience of transportation networks with deteriorating components. Journal of Structural Engineering [online]. 2016, 142(8), p. C4015015. ISSN 0733-9445, eISSN 1943-541X. Available from: https://doi.org/10.1061/(ASCE)ST.1943-541X.0001399

[22] REGGIANI, A., NIJKAMP, P., LANZI, D. Transport resilience and vulnerability: the role of connectivity. Transport Research, Part A: Policy \& Practice [online]. 2015, 81, p. 4-15. ISSN 0965-8564, eISSN 1879-2375. Available from: https://doi.org/10.1016/j.tra.2014.12.012

[23] BHAVATHRATHAN, B. K., PATIL, G. R. Capacity uncertainty on urban road networks: a critical state and its applicability in resilience quantification. Computers, Environment and Urban Systems [online]. 2015, 54, p. 108-118. ISSN 0198-9715. Available from: https://doi.org/10.1016/j.compenvurbsys.2015.07.005

[24] OMER, M., MOSTASHARI, A., NILCHIANI, R. Assessing resilience in a regional road-based transportation network. International Journal of Industrial and Systems Engineering [online]. 2013, 13(4), p. 389-408. ISSN 1748-5037, eISSN 1748-5045. Available from: https://doi.org/10.1504/IJISE.2013.052605

[25] MATTSSON, L. G., JENELIUS, E. Vulnerability and resilience of transport systems: a discussion of recent research. Transport Research, Part A: Policy \& Practice [online]. 2015, 81, p. 16-34. ISSN 0965-8564, eISSN 1879-2375. Available from: https://doi.org/10.1016/j.tra.2015.06.002

[26] MILLER-HOOKS, E., ZHANG, X., FATURECHI, R. Measuring and maximizing resilience of freight transportation networks. Computers and Operations Research [online]. 2012, 39(7), p. 1633-1643. ISSN 0305-0548, eISSN 1873-765X. Available from: https://doi.org/10.1016/j.cor.2011.09.017

[27] TAMVAKIS, P., XENIDIS, Y. Resilience in transportation systems. Procedia-Social and Behavioral Sciences [online]. 2012, 48, p. 3441-3450. eISSN 1877-0428. Available from: https://doi.org/10.1016/j.sbspro.2012.06.1308

[28] COX, A., PRAGER, F., ROSE, A. Transportation security and the role of resilience: a foundation for operational metrics. Transport Policy [online]. 2011, 18(2), p. 307-317. ISSN 0967-070X, eISSN 1879-310X. Available from: https://doi.org/10.1016/j.tranpol.2010.09.004

[29] HROMADA, M. Technologicke aspekty ochrany kritickej infrastruktury SR / Technological aspects of critical infrastructure protection in Slovakia (in Slovak). Dissertation. Zlin: Tomas Bata University in Zlin, 2011.

[30] SHAFIEEZADEH, A., BURDEN, L. I. Scenario-based resilience assessment framework for critical infrastructure systems: case study for seismic resilience of seaports. Reliability Engineering and System Safety [online]. 2014, 132, p. 207-219. ISSN 0951-8320. Available from: https://doi.org/10.1016/ 10.1016/j.ress.2014.07.021

[31] GOPALAKRISHNAN, K., PEETA, S. Sustainable and resilient critical infrastructure systems: simulation, modeling and intelligent engineering. Springer, 2010, p. 84-91. ISBN 978-3-642-11405-2.

[32] BRUNEAU, M., REINHORN, A. Seismic resilience of communities - conceptualization and operationalization. International Workshop on Performance Based Seismic-Design : proceedings. 2004.

[33] O'ROURKE, T. D. Critical infrastructure, interdependencies and resilience. Bridge. 2007, 37(1), p. 22-29. ISSN 0077-5614.

[34] REHAK, D., SENOVSKY, P., SLIVKOVA, S. Resilience of critical infrastructure elements and its main factors. Systems [online]. 2018, 6(21), p. 1-13. eISSN 2079-8954. Available from: https://doi.org/10.3390/systems6020021

[35] SHEFFI, Y. R. J. The resilient enterprise: overcoming vulnerability for competitive advantage. MIT Press, 2005. ISBN 978-0262693493. 
[36] U. S. Department of Homeland Security. Critical infrastructure resilience final report and recommendations. Washington D.C., 2009.

[37] TAYLOR, M. A. P. Vulnerability analysis for transportation networks. Elsevier, 2017. ISBN 9780128110102, eISBN 9780128110119.

[38] KAHAN, J. H., ALLEN, A. C., GEORGE, J. K. An operational framework for resilience. Journal of Homeland Security and Emergency Management [online]. 2009, 6(1). eISSN 1547-7355. Available from: https://doi.org/10.2202/1547-7355.1675

[39] BRUNEAU, M., REINHORN, A. Exploring the concept of seismic resilience for acute care facilities. Earthquake Spectra. 2007, 23, p. 41-62. ISSN 8755-2930.

[40] FERRARIOA, E., PEDRONIA, N., ZIOA, E. Evaluation of the robustness of critical infrastructures by hierarchical graph representation, clustering and Monte Carlo simulation. Reliability Engineering and System Safety [online]. 2016, 155, p. 78-96. ISSN 0951-8320. Available from: https://doi.org/10.1016/j.ress.2016.06.007

[41] MARTINEZ-PASTOR, B., NOGAL, M., O'CONNOR, A., CAULFIELD, B. Evaluation of resilience in traffic networks: models and characteristics. Irish Transport Research Network : proceedings. 2015.

[42] LUKAS, L., HROMADA, M. Resilience as main part of protection of critical infrastructure. International Journal of Mathematical Models and Methods in Applied Sciences [online]. 2011, 5, p. 1135-1142. ISSN 1998-0140. Available from: http://www.naun.org/main/NAUN/ijmmas/20-879.pdf

[43] ASBJORNSLETT, B. E. Assess the vulnerability of your production system. Production Planning and Control [online]. 1999, 10, p. 219-229. ISSN 0953-7287, eISSN 1366-5871. Available from: https://doi.org/10.1080/095372899233181

[44] BRUNEAU, M., CHANG, S., EGUCHI, R., LEE, G., O’ROURKE, T., REINHORN, A., SHINOZUKA, M., TIERNEY, K., WALLACE, W., VON WINTERFELT, D. A framework to quantitatively assess and enhance the seismic resilience of communities. Earthquake Spectra [online]. 2003, 19, p. 733-752. ISSN 8755-2930. Available from: https://doi.org/10.1193/1.1623497

[45] DANG, Y. Model on transportation demand distribution. 7th International Joint Conference on Computational Sciences and Optimization : proceedings [online]. 2014. Available from: https://doi.org/10.1109/cso.2014.109

[46] HOWARD, R. A., MATHESON, J. E. Influence diagrams. In: The principles and applications of decision analysis Vol. II. HOWARD, R. A., MATHESON, J. E. (eds.). Strategic Decisions Group, 1984, p. 721-762.

[47] TITKO, M., ZAGORECKI, A. Modelling vulnerability of critical infrastructure of transportation network using influence diagrams. Communications - Scientific Letters of the University of Zilina [online]. 2013, 15(4), p. 58-62. ISBN 1335-4205, eISSN 2585-7878. Available from: http://komunikacie.uniza.sk/index.php/communications/article/ view/711

[48] CERE, G., REZGUI, Y., ZHAO, W. Urban-scale framework for assessing the resilience of buildings informed by a Delphi expert consultation. International Journal of Disaster Risk Reduction [online]. 2019, 36, p. 101079. eISSN 2212-4209. Available from: https://doi.org/10.1016/j.ijdrr.2019.101079

[49] MOGHADAS, M., ASADZADEH, A., VAFEIDIS, A., FEKETE, A., KOTTER, T.A multi-criteria approach for assessing urban flood resilience in Tehran, Iran. International Journal of Disaster Risk Reduction [online]. 2019, 35, p. 101069. eISSN 2212-4209. Available from: https://doi.org/10.1016/j.ijdrr.2019.101069

[50] DILlEY, M., BOUDREAU, T. E. Coming to terms with vulnerability: a critique of the food security definition. Food Policy. 2001, 26, p. 229-247. ISSN 0306-9192.

[51] WISNER, B., BLAIKIE, P., CANNON, T., DAVIS, I. At risk: natural hazards, people's vulnerability and disasters. 2. ed. London: Routledge, 2004. ISBN 0415252156.

[52] DEVANANDHAM, H., RAMIREZ-MARQUEZ. J. Generic metric and quantitative approaches for system resilience as a function of time. Reliability Engineering and System Safety [online]. 2012, 99, p. 114-122. ISSN 0951-8320. Available from: https://doi.org/ 10.1016/j.ress.2011.09.002

[53] SLIVKOVA, S., REHAK, D., NESPOROVA, V., DOPATEROVA, M. Correlation of core areas determining the resilience of critical infrastructure. Procedia Engineering [online]. 2017, 192, p. 812-817. 2017, p.812-817. eISSN 1877-7058. Available from: https://doi.org/10.1016/j.proeng.2017.06.140

[54] ROSE, A. Economic resilience to natural and man-made disasters: multidisciplinary origins and contextual dimensions. Environmental Hazards [online]. 2007, 7(4), p. 383-398. ISSN 1747-7891, eISSN 1878-0059. Available from: https://doi.org/10.1016/j.envhaz.2007.10.001 